Donald, F. (2011, Février). Les pratiques avancées en pédiatrie dans le monde [International paediatric advanced practice nursing - translated to French]. Cahiers de la Puéricultrice, 244, 16-20. doi:CAHPUE-02-2011-48-244-0007-9820-101019-201100983

\title{
Paediatric Advanced Practice Nursing
}

Faith Donald, NP-PHC, PhD

Associate Professor, Daphne Cockwell School of Nursing

Ryerson University

350 Victoria Street

Toronto, ON M5B 2K3

Canada

fdonald@ryerson.ca

\section{5- 10 key Highlights of Article}

1. Internationally, the establishment of advanced practice nursing roles has occurred over the past 50 years in an ad hoc manner, dependent on the needs within particular regions and health care facilities.

2. The term "advanced practice nursing" is a broad term encompassing several roles that have various titles. The most common titles are: nurse practitioner (NP), clinical nurse specialist (CNS), nurse anesthetist and nurse midwife.

3. CNS and NP education is typically provided at the graduate level.

4. Paediatric NPs and CNSs work in a variety of community and hospital settings, such as hospital clinics, private paediatric practices, intensive care units and emergency departments and care for patients with all types of needs

5. Paediatric NPs are performing invasive procedures such as lumbar punctures, chest tube insertions, endotracheal intubation and central line placement. The literature indicates 
that they are capable and safe to do these procedures, when given appropriate training and initial supervision. Additional research is needed regarding the effectiveness of paediatric CNS roles.

6. Countries such as France, that are considering the implementation of paediatric NP and CNS roles are advised to follow an established process to determine health care needs and the best roles to meet those needs. A process that is being used in a variety of settings and countries is the participatory, evidence-based, patient-focused process for advanced practice nursing (APN) role development, implementation, and evaluation, the PEPPA framework.

7. Consistency in role titles and definitions and clear role expectations will facilitate planning, implementation and evaluation of the new role.

8. Based on the experiences of other countries, graduate level education is recommended for new advanced practice nursing roles.

9. Prevalent needs that might be addressed by advanced practice nurses include chronic disease management and/or health promotion.

10. Advanced practice roles offer exciting opportunities for improvements in patient care and professional growth for nurses. 


\begin{abstract}
This paper presents a review of the literature regarding the development of the paediatric NP and CNS roles; the education requirements in four countries where these roles are established; effectiveness of the paediatric NP and CNS roles within some settings in which they practice; and makes recommendations for the development of paediatric advanced practice nursing roles in countries that are considering implementing advanced practice nursing roles.
\end{abstract}




\section{Introduction}

Key elements of health care reform to advance the quality of care in France include increased emphasis on health promotion and disease prevention, improved access to care, and enhanced chronic disease management. An important component of this reform is the use of multidisciplinary teams that include nurses working in advanced practice roles $(1 ; 2)$. The term "advanced practice nursing" is a broad term (3) encompassing several roles that have various titles (4). The most common titles are: nurse practitioner (NP), clinical nurse specialist (CNS), nurse anesthetist and nurse midwife (5). The Nurse Practitioner/Advanced Practice Network of the International Council of Nurses (6) defines a nurse practitioner and/or advanced practice nurse as, "a registered nurse who has acquired the expert knowledge base, complex decision-making skills and clinical competencies for expanded practice, the characteristics of which are shaped by the context and/or country in which s/he is credentialed to practice. A Master's degree is recommended for entry level." The NP and CNS are the most common paediatric advanced practice nursing roles and are the subject of this paper. These two roles will be described in general terms related to role responsibilities, as titles and definitions of these roles vary within and across countries $(7 ; 8)$.

This paper presents a review of the literature regarding the development of two common advanced practice nursing roles in paediatrics, specifically the paediatric NP and CNS roles; the education requirements in four countries (the United States, Canada, United Kingdom and Australia) where these roles are established; effectiveness of the paediatric NP and CNS roles within some settings in which they work; and makes recommendations for the development of paediatric advanced practice nursing roles in countries, such as France, that are considering implementing advanced practice nursing roles.

\section{Background}


The NP role provides a variety of services that have traditionally been performed by physicians. For example, NPs assess, diagnose and manage acute and chronic conditions; prescribe drugs; and order laboratory and diagnostic imaging tests $(6 ; 9 ; 10)$. The NP role reduces demands on physicians' time and frees up the physician to care for complex cases.

The primary care setting was the first setting in which NPs worked (11). A systematic review completed when the NP role was relatively new compared NP with physician care in primary care settings (12). Horrocks et al. found the NPs had higher patient satisfaction ratings and patient health status outcomes were equal, with some improved quality of care (12). No differences were found in prescriptions, follow-up appointments or referrals; however, the NPs had slightly longer consultations (3.67 minutes) and did more investigations than the physicians. It is important to note that in addition to primary care NPs now work across all health care settings, such as hospitals, ambulatory clinics, rehabilitation centers and chronic care.

The CNS role is usually found in hospitals or chronic care, where CNSs promote quality improvement initiatives and provide nursing leadership and education to support high standards of nursing care and patient safety $(6 ; 13)$. Core components of the CNS role include clinical practice, education, research and leadership (1). Clinical expertise in a specialized area of practice, such as paediatrics, is a key characteristic of the CNS role. The use of advanced practice nursing skills to provide care for patients and families with complex needs is a critical feature of both the NP and CNS roles.

\section{Literature Search}

A review of the literature was conducted in CINAHL, Medline, PubMed, and Web of Science. The search terms included "advanced practice nurs*", "nurse practitioner", "clinical nurse specialist", "pediatric*", "child*". The search was from the beginning of each database to 
December of 2010 and restricted to the English language. Relevant articles were identified and representative documents are reported in this paper. Information was also obtained through professional organizations, academic settings and government websites.

\section{Development of Advanced Practice Nursing Roles in Paediatrics}

Internationally, the establishment of advanced practice nursing roles has occurred over the past 50 years in an ad hoc manner, dependent on the needs within particular regions and health care facilities (4). The NP and CNS roles emerged in Canada and the Unites States in the 1960s, the United Kingdom in the 1970s and 80s, and Australia for the CNS role in the late 1980s and the NP role in 2001 (4;14-16). Worldwide, the first NP education program was in the 1960s and focused on paediatrics (17-19). These early paediatric NPs worked in primary care and paediatrician offices. Nearly 30 years later, acute care paediatric NP education programs were established and the graduates began working in critical care areas in hospitals in the mid1990s (20).

The CNS role was introduced to support and improve the quality of nursing care at a time of increasing specialization, technology, patient acuity and complexity of health care (14). A PhD program at the University of Pittsburgh was the first reported CNS program to offer specialization in maternity and paediatrics (21). The earliest paediatric CNSs worked in hospitals. The first literature identified regarding the paediatric CNS was published in 1970 and described the early role (22). Opportunities for CNSs to obtain certification in paediatrics have been offered for a number of years in the United States (p. 154-155) (23). Certification is an additional test with ongoing educational requirements to ensure that the paediatric CNS has demonstrated and maintains up-to-date knowledge regarding practice standards. Worldwide, the first paediatric advanced practice nurse association, the Association of Pediatric Nurse 
Associates and Practitioners was formed in the United States in 1973; paediatric nurse practitioners were first certified in 1977 (24).

\section{Educational Requirements}

Education programs are vital to ensure appropriate knowledge and skills for advanced practice nurses and to provide continuing education to promote current standards of practice. Over the past 50 years, educational requirements for NPs and CNSs in the United States and Canada have generally progressed from continuing education, post-diploma or postbaccalaureate programs (25-29) to the current requirement for a master's or doctoral degree $(5 ; 6 ; 30)$. The enhanced level of education is justified by the greater volume of knowledge required to provide quality care, the increasing complexity of the health care system, nursing shortages and advances in technology. These factors may also be linked to the increased number of institutions offering nursing graduate degree programs. However, the educational requirements for NPs and CNSs vary across and within countries. For instance, the province of Ontario in Canada continues to graduate some primary health care NPs at the post-baccalaureate certificate level, while others graduate at the master's level (29). All other specialty NP education programs in Canada are only offered at the master's degree level. The neonatal NP is educated in a separate education program than the paediatric NP in the Unites States and Canada, but both countries require a graduate degree for paediatric NPs and neonatal NPs.

The United States recently recommended an increase in the educational requirement for NPs and CNSs to a doctorate in nursing practice (5). In addition to the changes in education requirements, CNSs in the United States will prescribe drugs, order laboratory and diagnostic tests and other patient care activities that were not typically associated with the CNS role in the past. In Australia, a master's degree is required for both the NP and CNS roles (1). The United 
Kingdom has a combination of certificate and master's level NP programs and has recently developed the paediatric NP specialization $(1 ; 31)$. However, in the United Kingdom a first-level or bachelor degree remains the minimum qualification to become an NP or CNS, when combined with work experience and workplace training (1). Courses are offered for all registered nurses interested in expanding their scope of practice in specific areas, such as prescribing drugs.

Canada does not offer specific CNS programs (29); nursing specialization is provided by colleges at the certificate level in most provinces. Although, in 1970, the University of Toronto was the first Canadian university to offer a graduate program with a focus on clinical nursing specialization (32).

Common curriculum components for NPs and CNSs cover three areas of knowledge. Firstly, concepts and issues intrinsic to graduate nursing education are taught, such as nursing theory, research and ethics. Secondly, knowledge and skills required for advanced practice, for example pathophysiology, advanced physical assessment and pharmacology. Thirdly, knowledge and skill for specialty practice, such as paediatric cardiology, oncology or primary care $(33 ; 34)$.

While a paediatric NP education program was the first NP education program in the world, many paediatric NPs are currently taught in primary care NP programs, and then specialize in paediatrics in their work settings.(33) In the Unites States, post-master's degree and post-doctoral degree internships provide intense clinical practice learning for NPs and CNSs in paediatric specialty roles.

\section{Effectiveness of NPs and CNSs in Various Practice Settings}

Paediatric NPs and CNSs work in a variety of community and hospital settings, such as hospital clinics, private paediatric practices, intensive care units and emergency departments and care for patients with all types of needs (20;35-50). NPs counsel children and families, prescribe 
medications, perform invasive procedures and a variety of other advanced practice nursing interventions, depending on the needs of patients, families and the organization in which the NP practices. The CNS also provides direct patient care, but typically the main focus of the CNS role is to provide leadership and improve quality of nursing care by consulting with and being a role model for staff nurses (51). There may be both CNSs and NPs working in the same setting. For instance, the Hospital for Sick Children in Canada developed the paediatric CNS role in the 1970s and now has both NPs and CNSs actively involved in patient care and quality improvement (52). A number of research studies have evaluated the effectiveness of paediatric NP and CNS roles and a sampling of the research that reflects typical findings is presented. An interprofessional survey of 655 health professionals in the United States and Canada was conducted to define the NP role in neonatal intensive care units. The researchers concluded that the neonatal NP role incorporated components of both the NP and CNS roles, including advanced clinical practice, education, research and administration (53). Several studies' findings indicate that the neonatal NP provides care equivalent to and/or better than physician residents (54-56). Lee et al. (57) determined that neonatal NPs conducting routine examinations of newborns were significantly more likely to detect abnormalities than senior house officers. As well, parent satisfaction with neonatal NP care has been found to be equivalent to care provided by physician residents (55).

Fanta et al. (58) used a randomized study in a paediatric trauma center in the United States and found equivalent patient outcomes and a dramatically reduced length of stay for injured children when monitored by the paediatric NP compared with those monitored by resident physicians. There was no increase in complications associated with the shorter length of stay and the patient outcomes were equal between the two groups. Patient/family satisfaction 
with numbers of visits to the bedside and information about injuries, tests and treatments was significantly higher for those cared for by the NPs compared to resident physicians. Shebesta et al. (59) evaluated the care of trauma victims delivered by paediatric NPs versus medical residents. They found the NP care was equivalent to that of the medical residents and staff nurses were more satisfied with NP care.

In 1989, Nemes et al. (60) conducted a study of paediatric NPs caring for surgical patients in a teaching hospital in the United States. Nearly all of the surgeons (90\%) reported that the NPs improved communication between the patients and physicians and $83 \%$ of the surgeons reported that the NPs did not interfere with education of the medical resident. The paediatric NPs assessed and wrote orders for patients in the hospital; provided staff, patient and family education; and assisted with policy development. An added benefit of paediatric NPs working in surgical units is their availability to provide care when the surgeon is not accessible.(18)

Paediatric NPs are performing invasive procedures such as lumbar punctures, chest tube insertions, endotracheal intubation and central line placement $(61 ; 62)$. The literature indicates that they are capable and safe to do these procedures, when given appropriate training and initial supervision.

While there were a number of studies that described the CNS role and program implementation, only two evaluation studies were identified. Lowes (63) evaluated the specialist nurse role when caring for children with diabetes. Findings revealed the introduction of successful home management plans, a decrease of nearly $50 \%$ in the length of stay in the hospital for those initially hospitalized, readmission length of stay guidelines were met, education sessions were initiated and there was a substantial reduction in clinic non-attendance. However, there was an increase in readmission rates for children with established diabetes. 
Damato et al. (64) examined the association between the amount of time (direct and administrative) spent by CNSs with families of very low birth weight infants and infant outcomes (rehospitalizations and acute care visits) following initial discharge from hospital. "After discharge there were significant relationships between the amount of CNS direct care time and the number of acute care visits $(\mathrm{r}=0.45, \mathrm{p}<0.01)$ and infant rehospitalizations $(\mathrm{r}=0.51, \mathrm{p}<$ 0.01)" (p. 75). The study did not show improved infant outcomes related to the amount of time spent with the infants and families. Additional research is needed regarding the effectiveness of paediatric CNS roles.

\section{Recommendations for the Development of NP and CNS Roles}

Countries such as France, where paediatric nurses seek recognition of their specialty in advanced practice nursing are advised to follow an established process to determine health care needs and whether the CNS or NP role is best suited to meet those needs. A process that is being used in a variety of settings and countries is the participatory, evidence-based, patient-focused process for advanced practice nursing (APN) role development, implementation, and evaluation, the PEPPA framework (65).

An examination of the patient population and current model of care is the first step in this process (65). A comprehensive needs assessment with stakeholders including paediatricians and children's hospitals, accompanied by an assessment of health human resources and health care policies in France and Europe is critical for determining needs and if a new model of care is warranted. The next step in the process is to determine goals and the new model of care or program, and then decide if an advanced practice nursing role is needed to help meet the goals. If an advanced practice role is needed, systematic planning of implementation strategies will be crucial including regulations and legislation, remuneration, identifying outcomes and the 
evaluation plan, the collection of baseline data, barriers to and facilitators of role implementation in other countries, education programs and supports for the program and administrative supports and resources. Role development will require policies and procedures and decisions regarding collaborative practice models with physicians and other health care providers. Paediatricians and children's hospitals will be key partners and supports for educational and employment endeavors. Once the role is established and the NP or CNS has had time to become proficient in the new role, research is needed to evaluate the role and the new model of care. Evaluation over time will be important in order to ensure quality improvement and identify additional unmet needs.

Consistency in role titles and definitions and clear role expectations (8) will facilitate planning, implementation and evaluation of the new role. Based on the experiences of other countries, graduate level education is recommended. Prevalent needs that might be considered initially include chronic disease management and/or health promotion. Advanced practice roles offer exciting opportunities for improvements in patient care and professional growth for nurses. A systematic process to initiate these roles will help to ensure that the implementation is a success. 


\section{Reference List}

(1) Delamaire ML, Lafortune G. OECD Health Working Paper No. 54. Nurses in advanced roles: A description and evaluation of experiences in 12 developed countries.

Organization for Economic Cooperation and Development. 2010 [cited 2010 Jul 12];1106. Available from: http:/www.oecd.org/els/health/workingpapers

(2) Bourgueil Y. National recommendation for professional skill mix. Health Policy Monitor. 2008 [cited 2011 Jan 2];AprilAvailable from:

PrFont34Bin0BinSub0Frac0Def1Margin0Margin0Jc1Indent1440Lim0Lim1 http://www.h pm.org/survey/fr/a11/1

(3) Bryant-Lukosius D, DiCenso A, Browne G, Pinelli J. Advanced practice nursing roles: Development, implementation and evaluation. Journal of Advanced Nursing 2004 Dec;48(5):519-29.

(4) Duffield C, Donoghue J, Pelletier D. CNSs' perceptions of role competencies: One Australian perspective. Clinical Nurse Specialist: The Journal for Advanced Nursing Practice 1995;9(1):13-22.

(5) APRN Consensus Work Group, National Council of State Boards of Nursing APRN Advisory Committee. Consensus Model for APRN Regulation: Licensure, Accreditation, Certification \& Education. American Association of Colleges of Nursing. 2008 [cited 2010 Dec 28];1-41. Available from: http://www.aacn.nche.edu/education/pdf/APRNReport.pdf

(6) Nurse Practitioner/Advanced Practice Network. Frequently asked questions: What is a nurse practitioner/advanced practice nurse (NP/APN)? International Council of Nurses. 2010 [cited 2011 Jan 2];Available from: http://icn-apnetwork.org/

(7) Lary MJ, Lavigne SE, Muma RD, Jones SE, Hoeft HJ. Breaking down barriers: Multidisciplinary education model. Journal of Allied Health 1997;26(2):63-9.

(8) Donald F, Bryant-Lukosius D, Martin-Misener R, Kaasalainen S, Kilpatrick K, Carter N, et al. Clinical nurse specialists and nurse practitioners: Title confusion and lack of role clarity. CAN J NURS LEADERSH 2011;24(March Special Issue) In press 2011.

(9) Donald F, Martin-Misener R, Bryant-Lukosius D, Kilpatrick K, Kaasalainen S, Carter N, et al. The primary health care nurse practitioner role in Canada. CAN J NURS LEADERSH 2011;24(March Special Issue) In press 2011.

(10) Kilpatrick K, Harbman P, Carter N, Martin-Misener R, Bryant-Lukosius D, Donald F, et al. The acute care nurse practitioner role in Canada. CAN J NURS LEADERSH 2011;24(March Special Issue) In press 2011. 
(11) Silver HK, Ford LC, Day LR. The pediatric nurse-practitioner program: Expanding the role of the nurse to provide increased health care for children. JAMA $1968 \mathrm{Apr}$ 22;204(4):298-302.

(12) Horrocks S, Anderson E, Salisbury C. Systematic review of whether nurse practitioners working in primary care can provide equivalent care to doctors. British Medical Journal 2002 Apr 6;324(7341):819-23.

(13) Bryant-Lukosius D, Carter N, Kilpatrick K, Martin-Misener R, Donald F, Kaasalainen S, et al. The clinical nurse specialist role in Canada. CAN J NURS LEADERSH 2011;24(March Special Issue) In press 2011.

(14) Canadian Nurses Association. Position statement: Clinical nurse specialist. Author. 2009 [cited 2010 Jun 27];1-5. Available from: http://www.cnanurses.ca/CNA/documents/pdf/publications/PS104_Clinical_Nurse_Specialist_e.pdf

(15) Wilson A, Shifaza F. An evaluation of the effectiveness and acceptability of nurse practitioners in an adult emergency department. INT J NURS PRACT 2008 Apr;14(2):149-56.

(16) Australian College of Nurse Practitioners. What is a nurse practitioner? Australian College of Nurse Practitioners. 2011Available from: http://www.acnp.org.au/content/what-is-a-nurse-practitioner.html

(17) Silver HK, Ford LC, Stearly SG. A program to increase health care for children: The pediatric nurse practitioner program. Pediatrics 1967 May;39(5):756-60.

(18) Kline AM, Sorce L, Reider-Demer M, Widecan M, Jones DC, Goodhue C. Letters to the editor... Reider-Demer M, Widecan M, Jones DC et al. (2006). The evolving responsibilities of the pediatric nurse practitioner. Journal of Pediatric Health Care, 20, 280-3. Journal of Pediatric Healthcare 2007 Mar;21(2):134-5.

(19) Schiff DW, Fraser CH, Walters HL. The pediatric nurse practitioner in the office of pediatricians in private practice. Pediatrics 1969 Jul;44(1):62-8.

(20) Clinton P, Sperhac AM. Professional issues. The acute care pediatric nurse practitioner. Journal of Pediatric Healthcare 2005 Mar;19(2):117-20.

(21) Rubin R. Graduate programs in maternity and pediatric nursing leading to the degree of doctor of philosophy at the University of Pittsburgh. Extending the Boundaries of Nursing Education. New York: National League for Nursing; 1969. p. 22-7.

(22) Miles MR. The clinical specialist in pediatrics. Mo Nurse 1970;39(5):3-4.

(23) Duffy M. Obtaining certification: Considering the options. In: Duffy M, Dresser S, Fulton JS, editors. Clinical Nurse Specialist Toolkit: A Guide for the New Clinical Nurse Specialist. New York: Springer; 2009. p. 153-8. 
(24) Taylor MK. Mapping the literature of pediatric nursing. Journal of the Medical Library Association 2006;94(2 Suppl):E128-E136.

(25) Advisory Committee on Health Human Resources. The nature of the extended/expanded nursing role in Canada: Final report to Health Transition Fund Secretariat. Ottawa, ON: Health Transition Fund; 2001. Report No.: NA 321.

(26) Chambers LW, Suttie B, Summers V. Expanded role nurses: An education program in Newfoundland and Labrador. Canadian Journal of Public Health Revue Canadienne de Santé Publique 1974;65(4):273-6.

(27) Jones PE, Parker NI. Education for the nurse in primary care. Nursing Papers 1974;6(2):57-64.

(28) Riley I. The B.Sc.N. graduate as a nurse practitioner. Nursing Papers 1974;6(2):19-20.

(29) Martin-Misener R, Bryant-Lukosius D, Harbman P, Donald F, Kaasalainen S, Carter N, et al. Education of advanced practice nurses in Canada. CAN J NURS LEADERSH 2011;24(March Special Issue) In press 2011.

(30) Beloff JS, Korper M. The health team model and medical care utilization. Effect on patient behavior of providing comprehensive family health services. JAMA 1972 Jan 17;219(3):359-66.

(31) Royal College of Nursing. Advanced Nurse Practitioners-an RCN Guide to the Advanced Nurse Practitioner Role, Competences and Programme Accreditation. Royal College of Nursing. 2010 [cited 2011 Jan 3];1-35. Available from: http://www.rcn.org.uk/_data/assets/pdf_file/0003/146478/003207.pdf

(32) Montemuro MA. The evolution of the clinical nurse specialist: Response to the challenge of professional nursing practice. Clinical Nurse Specialist: The Journal for Advanced Nursing Practice 1987 Sep;1(3):106-10.

(33) Brundige KJ. Professional insights. Preparing pediatric nurse practitioners for roles in specialty practice. Journal of Pediatric Healthcare 1997 Jul;11(4):198-200.

(34) King KB, Ackerman MH. An educational model for the acute care nurse practitioner. CRIT CARE NURS CLIN NORTH AM 1995 Mar;7(1):1-7.

(35) Reider-Demer M, Widecan M, Jones DC, Goodhue C. Professional issues. The evolving responsibilities of the pediatric nurse practitioner. Journal of Pediatric Healthcare 2006 Jul;20(4):280-3.

(36) Organ K, Chinnick P, Higgison I, Stanhope B, Hoskins R, Benger J. Evaluating the introduction of a paediatric emergency nurse practitioner service. Emergency Nurse 2005 Nov;13(7):8-11. 
(37) Borgmeyer A, Gyr PM, Jamerson PA, Henry LD. Evaluation of the role of the pediatric nurse practitioner in an inpatient asthma program. Journal of Pediatric Healthcare 2008 Sep;22(5):273-81.

(38) Cruikshank BM, Clow TJ, Seals B. Pediatric nurse practitioner functions in the outpatient clinics of a tertiary care center. MED CARE 1986 Apr;24(4):340-9.

(39) Rodriguez KA, Goodhue CJ, Upperman JS. Pediatric nurse practitioner implementation of a pediatric trauma continuity clinic utilizing the "medical home" model. Journal of Trauma Nursing 2010 Apr;17(2):64-8.

(40) Lindeke LL, Leonard BJ, Presler B, Garwick A. Family-centered care coordination for children with special needs across multiple settings. Journal of Pediatric Healthcare 2002 Nov;16(6):290-7.

(41) Webster-Stratton C, Glascock J, McCarthy AM. Nurse practitioner-patient interactional analyses during well-child visits. Nursing Research 1986 Jul;35(4):247-9.

(42) Cruikshank BM, Clow TJ, Seals B. Pediatric nurse practitioner functions in the outpatient clinics of a tertiary care center. MED CARE 1986 Apr;24(4):340-9.

(43) Rance KS, Trent CA. Profile of a primary care practice asthma program: Improved patient outcomes in a high-risk population. Journal of Pediatric Healthcare 2005 Jan;19(1):25-32.

(44) Dearmun A, Gordon K. The nurse practitioner in children's ambulatory care. Paediatric Nursing 1999 Feb;11(1):18-21.

(45) DiMarco MA, Huff M, Kinion E, Kendra MA. The pediatric nurse practitioner's role in reducing oral health disparities in homeless children. Journal of Pediatric Healthcare 2009 Mar;23(2):109-16.

(46) Christensen J, Akcasu N. The role of the pediatric nurse practitioner in the comprehensive management of pediatric oncology patients in the inpatient setting... including commentary by Rasco C. Journal of Pediatric Oncology Nursing 1999 Apr;16(2):58-67.

(47) Loranger $\mathrm{N}$. The clinical nurse specialist as a consultant for play on the pediatric bone marrow transplant unit. Clinical Nurse Specialist: The Journal for Advanced Nursing Practice 1992 Dec;6(4):176-8.

(48) Kearney JA, Yurick CM. Nurse to nurse referral: The role of the child psychiatric nurse consultant. Journal of Pediatric Healthcare 1996 May;10(3):115-20.

(49) Hollis R. The role of the specialist nurse in paediatric oncology in the United Kingdom. European Journal of Cancer 2005;41(12):1758-64. 
(50) Rawe C, Trame CD, Moddeman G, O'Malley P, Biteman K, Dalton T, et al. Management of procedural pain: Empowering nurses to care for patients through clinical nurse specialist consultation and intervention. Clinical Nurse Specialist: The Journal for Advanced Nursing Practice 2009 May;23(3):131-7.

(51) Delametter G. Advanced Practice Nursing and the role of the Paediatric Critical Care Nurse Practitioner. Critical Care Nursing Quarterly 1999;21(4):16-21.

(52) LeGrow K, Hubley P, McAllister M. A conceptual framework for advanced practice nursing in a pediatric tertiary care setting: The SickKids' experience. CAN J NURS LEADERSH 2010 Jun;23(2):32-46.

(53) Hunsberger M, Mitchell A, Blatz S, Paes B, Pinelli J, Southwell D, et al. Definition of an advanced nursing practice role in the NICU: The clinical nurse specialist/neonatal practitioner. Clinical Nurse Specialist 1992;6(2):91-6.

(54) Mitchell A, Watts J, Whyte R, Blatz S, Norman GR, Guyatt GH, et al. Evaluation of graduating neonatal nurse practitioners. Pediatrics 1991 Oct;88(4):789-94.

(55) Mitchell-DiCenso A, Guyatt G, Marrin M, Goeree R, Willan A, Southwell D, et al. A controlled trial of nurse practitioners in neonatal intensive care. Pediatrics 1996 Dec;98(6:Pt 1):t-8.

(56) Aubrey WR, Yoxall CW. Evaluation of the role of the neonatal nurse practitioner in resuscitation of preterm infants at birth. Archives of Disease in Childhood -- Fetal \& Neonatal Edition 2001 Sep;85(2):F96-F99.

(57) Lee T, Skelton R, Skene C. Routine neonatal examination: Effectiveness of trainee paediatrician compared with advanced neonatal nurse practitioner. Archives of Disease in Childhood Fetal and Neonatal Edition 2001;85:f100-f104.

(58) Fanta K, Cook B, Falcone RA, Jr., Rickets C, Schweer L, Brown RL, et al. Pediatric trauma nurse practitioners provide excellent care with superior patient satisfaction for injured children. Journal of Pediatric Surgery 2006 Jan;41(1):277-81.

(59) Shebesta KF, Cook B, Rickets C, Schweer L, Brown RL, Garcia VF, et al. Pediatric trauma nurse practitioners increase bedside nurses' satisfaction with pediatric trauma patient care. Journal of Trauma Nursing 2006 Apr;13(2):66-9.

(60) Nemes J, Barnaby K. The pediatric nurse practitioner in a surgical inpatient setting. NURS MANAGE 1992;23(1):44-6.

(61) Verger JT, Marcoux KK, Madden MA, Bojko T, Barnsteiner JH. Nurse practitioners in pediatric critical care: Results of a national survey. AACN CLIN ISSUES ADV PRACT ACUTE CRIT CARE 2005 Jul;16(3):396-408. 
(62) Molitor-Kirsch S, Thompson L, Milonovich L. The changing face of critical care medicine: Nurse practitioners in the pediatric intensive care unit. AACN CLIN ISSUES ADV PRACT ACUTE CRIT CARE 2005 Apr;16(2):172-7.

(63) Lowes L. Specialist nursing. Evaluation of a paediatric diabetes specialist nurse post. British Journal of Nursing (BJN) 1997 Jun 12;6(11):625.

(64) Damato EG, Dill PZ, Gennaro S, Brown LP, York R, Brooten D. The association between CNS direct care time and total time and very low birth weight infant outcomes. Clinical Nurse Specialist: The Journal for Advanced Nursing Practice 1993 Mar;7(2):759.

(65) Bryant-Lukosius D, DiCenso A. A framework for the introduction and evaluation of advanced practice nursing roles. Journal of Advanced Nursing 2004 Dec;48(5):530-40. 